\title{
OLHARES E JOGOS NO ESPAÇO: TRADUZINDO SAINT-DENYS GARNEAU
}

\section{Genival Teixeira Vasconcelos Filho}

\section{Introdução}

A poesia de Saint-Denys Garneau supera as barreiras do distanciamento histórico e social, justamente por tratar de temas caros aos homens de todas as épocas: a inquietude, o sentimento de estranheza, de não pertencimento, temas universais que a colocam em diálogo com a poesia de grandes poetas, dos mais diversos lugares do planeta. Suas investigações poéticas, ainda que não tenham tido continuidade devido a sua decisão de parar de escrever, não ficam em débito com as elucubrações dos grandes poetas da literatura universal.

\section{Saint-Denys Garneau e o mal-estar no mundo: breve apresentação do poeta.}

Nascido em Montréal, aos 13 de junho de 1912, Hector de Saint-Denys Garneau foi um poeta canadense da província do Québec. Exerceu atividades variadas nos campos da arte e da comunicação, atuando como pintor e também crítico de artes junto ao grupo de intelectuais católicos responsável pela edição do periódico La Relève.

Garneau morreu prematuramente e não conheceu em vida a valorização de seu trabalho poético. Suas incursões no universo da poesia começaram cedo, quando em 1926, aos 14 anos, ganhou um prêmio do concurso promovido pela Galeria Morgan, em Montréal, por seu poema "Le dinosaure". Mas foi apenas em 1937 que Garneau ofertou ao mundo seu primeiro (e único) livro de poemas, Regards et jeux dans l'espace, editado pelo próprio poeta. As inovações estilísticas e a estética em desalinho com os padrões literários da época renderam-lhe um dissabor com a crítica do período, levandoo a desistir de sua carreira de poeta. Garneau temia a crítica de tal maneira, que o receio de não ser compreendido o fez retirar das prateleiras das livrarias a sua obra poética. "A crítica da época permanece hostil às correntes modernistas" (Gasquy-Resch, 1994, p. $117)^{1}$, e portanto essa hostilidade sequer permitia a compreensão do que havia de moderno em sua poesia. A utilização dos versos livres ia completamente contra os princípios clássicos que, segundo a crítica da época, fariam da poesia quebequense uma

\footnotetext{
${ }^{1}$ Tradução nossa, do original: "La critique de l'époque reste hostile aux courants modernistes".
} 
arte capaz de tornar grande e majestosa sua instituição Literatura.

Poderíamos dizer, segundo a teoria dos polissistemas (Even-Zohar, 2000, p. 199204) que a obra de Saint-Denys Garneau ocupou, naquele momento, um lugar mais periférico dentro do sistema literário quebequense. Porém, sua obra obteve reconhecimento póstumo e foi alçada, no decorrer dos anos, ao patamar de cânone literário representativo do mais alto refinamento estético da poesia do Québec, tendo influenciado as gerações posteriores e operando um deslocamento da periferia para o centro do referido sistema literário.

Algumas das razões do impacto negativo que Regards et jeux dans l'espace causou podem ser explicadas à luz do contexto literário da época. Ao se fazer uma leitura mais atenta da crítica literária do Québec no referido período, em especial a crítica sobre poesia (Gasquy-Resch, 1994), é possível perceber um movimento de afirmação da literatura quebequense, de uma literatura nacional. Na maior parte das sociedades modernas testemunhamos essa necessidade de afirmação de uma expressão genuinamente nacional, como foi o caso do projeto de Mário de Andrade no Brasil, por exemplo, um projeto de renovação estética do período em todas as esferas da arte, no início dos anos 1930 (Lafetá, 2000).

Essa necessidade surge primeiramente com os escritores, a crítica apenas a corrobora (ou refuta, em alguns casos) posteriormente. Não é raro que haja, no trabalho da crítica literária, uma distorção ou até mesmo uma incompreensão do trabalho dos escritores. No que diz respeito à poesia de Saint-Denys Garneau, não se pode dizer que a necessidade de afirmação de uma poesia nacional fizesse parte de seu projeto de escritura. ${ }^{2}$ Talvez esse tenha sido um fator de estranheza para a crítica.

O poeta temia a crítica de tal maneira que o receio de não ser compreendido o fez retirar do mercado seu primeiro e único livro de poesias. E de fato, o poeta foi acusado de produzir uma obra "obscura" e mesmo hermética, segundo as palavras do abade Camille Roy:

St-Denys Garneau publicou Regards et Jeux dans l'Espace (1937), uma coleção de poemas valéryanos, ou seja, quase que incompreensíveis. Há nestes poemas algum esforço, um certo labor, seja de introspecção ou de interpretação das coisas externas. Mas este esforço geralmente resulta no ininteligível. Para alguns, o hermetismo é sublime. $\mathrm{O}$ sublime é aqui muito velado. $\mathrm{O}$ espírito francês nunca irá acomodar um pensamento que não possa ver, tendo-o o poeta escondido sob o véu de um símbolo

\footnotetext{
${ }^{2}$ Primeiramente seu projeto era o de simplesmente seguir a carreira de escritor, "Mais il finit par douter de ses capacités" (GASQUY-RESCH, 1994: 117).
} 
muito obscuro. Mr. Garneau, aliás, escreve sem ponto ou vírgula. Isso faz parte de sua arte estranha ${ }^{3}$ (Roy, 1962).

Essa "arte estranha" é sem dúvida representativa de um poeta que forjou, através de uma linguagem aparentemente simples, uma poética do olhar e dos jogos no espaço muito a frente de seus contemporâneos. Não é de se surpreender que essa poética causasse estranhamento na maioria dos críticos de então.

Alguns elementos perceptíveis na poesia de Saint-Denys Garneau são o uso intenso de um certo ludismo na criação poética, o distanciamento do sublime e a falsa aparência de simplicidade na composição das imagens poéticas. A sintaxe truncada e contorcida pelos jogos poéticos de Garneau, bem como seu estilo de escritura poética, foram interpretados pela crítica do período sem levar em conta a estrutura global da obra (não apenas os aspectos formais e linguísticos, mas também semânticos e semióticos). Além dessas características, um outro fator coloca a poesia de Garneau em posição de vanguarda: a meditação profunda sobre a poesia e a linguagem enquanto busca de uma universalização das angústias existenciais. O trabalho do poeta vai se direcionar para uma busca completamente pessoal e pouco compreendida por seus contemporâneos. Ligado ao grupo de La Relève, que, a partir de 1934, trabalhou na renovação da literatura do Québec, Saint-Denys Garneau vê na poesia o caminho privilegiado de uma busca moral e espiritual estimulada por um tormento metafísico e religioso.

Os efeitos dessa busca se refletem no trabalho poético, fazendo da escritura um meio possível de expressão dos conflitos metafísicos. Porém, a agonia de não poder atingir seu objetivo em poesia e de ser mal compreendido pela crítica, entre outros fatores existenciais, se torna intensa.

Obscura ou incompreendida, o fato é que a poesia de Garneau não foi bem recebida pela crítica, ocupada em sua busca por uma literatura legitimamente nacional (plano maior da crítica literária quebequense do período).

Diante da crise existencial que se abateu sobre Saint-Denys Garneau, e da qual temos notícias graças ao seu Journal e às suas correspondências, o poeta decide se

\footnotetext{
${ }^{3}$ Tradução nossa, do original: "St-Denys Garneau a publié Regards et Jeux dans l'Espace (1937), recueil de poésies valéryennes, c'est-à-dire à peu près incompréhensibles. Il y a dans ces poèmes un effort certain, combien laborieux, soit d'introspection, soit d'interprétation des choses extérieures. Mais cet effort aboutit le plus souvent à l'inintelligible. Pour d'aucuns, l'hermétisme est du sublime. Le sublime est ici trop voilé. L'esprit français ne s'accommodera jamais d'une pensée qu'il ne peut apercevoir, le poète l'ayant cachée sous le boisseau d'un symbole trop obscur. M. Garneau, par surcroit, écrit sans points ni virgules. Cela fait partie de son art étrange."
} 
isolar dos meios literários:

Eu fiz um grande sacrifício: desisti dos meus sonhos e dos meus poemas. Não escrevo mais porque já não sonho, e já não sonho porque a gramática é o que melhor pode esterilizar uma inspiração. ${ }^{4}$

Só após a morte prematura, aos 31 anos, é que houve maior reconhecimento de sua efetiva contribuição para a poesia do Québec, e desde então têm sido constantes os estudos a respeito de sua obra. Aliás sua morte foi tão peculiar que, como era de se esperar, iniciou-se um processo de mitificação do poeta. Para ilustrar essa mitificação, vale transcrever um trecho da biografia detalhada de Garneau que consta no site oficial ${ }^{5}$ a ele dedicado:

No crepúsculo de um dia de outono, Hector de Saint-Denys Garneau rema sobre o rio em uma canoa, na esperança de recuperar sua barraca em uma ilha. Exausto, faz uma parada nas terras de Joseph-Louis Boucher, à procura de um telefone. Em seguida, retoma sua canoa e tenta subir o rio. Sentindo fraqueza, bate sua canoa na costa do rio e, num último esforço, dá alguns passos adiante, como numa última tentativa de desafiar sua morte iminente. Assim, em 24 de outubro de 1943, Hector de Saint-Denys Garneau sucumbe a um ataque cardíaco aos 31 anos de idade. ${ }^{6}$

Certo tempo depois de sua morte, o poeta é alçado à categoria de ícone nacional. Contudo, Saint-Denys Garneau permanece imortalizado, não por sua morte trágica e até mesmo poética, mas pelo conjunto de sua obra e por todo o legado que deixou não só para a literatura do Québec, mas para toda a posteridade.

\section{A poética de Saint-Denys Garneau em jogo}

Enumeremos [...] as características que consideramos próprias do jogo. É uma atividade que se processa dentro de certos limites temporais e espaciais, segundo uma determinada ordem e um dado número de regras livremente aceitas, e fora da esfera da necessidade ou da utilidade material. O ambiente em que ele se desenrola é de arrebatamento e entusiasmo, e torna-se sagrado ou festivo de acordo com a circunstância. A ação é acompanhada por um sentimento de exaltação e tensão, e

\footnotetext{
${ }^{4}$ In: GARNEAU, Saint-Denys. Journal, octobre 1929. Tradução nossa, do original: "J'ai fait un grand sacrifice: j'ai renoncé à mes rêves et à mes poèmes. Je n'écris plus parce que je ne rêve plus, et je ne rêve plus parce que la grammaire est bien ce qui peut le mieux stériliser une inspiration."

${ }^{5}$ http://www.saintdenysgarneau.com/

6 Disponível em: http://www.saintdenysgarneau.com/biographie.htm, último acesso em 02/11/2013. Tradução nossa, do original: “Au crépuscule d'un jour d'automne, Hector de Saint-Denys Garneau file sur la rivière en canot dans l'espoir de récupérer sa tente sur une île. Épuisé, il fait un arrêt sur la terre de Joseph-Louis Boucher, à la recherche d'un téléphone. Puis, il regagne son canot et tente de remonter la rivière. Se sentant défaillir, il fait échouer son canot sur la rive et, dans un dernier élan, avance de quelques pas, comme pour tenter une dernière fois de défier sa mort imminente. C'est ainsi que le 24 octobre 1943, Hector de Saint-Denys Garneau succombe à une crise cardiaque à l'âge de 31 ans."
} 
seguida por um estado de alegria e distensão.

Ora, dificilmente se poderia negar que estas qualidades também são próprias da criação poética. A verdade é que esta definição de jogo que agora demos também pode servir como definição da poesia. A ordenação rítmica ou simétrica da linguagem, a acentuação eficaz pela rima ou pela assonância, o disfarce deliberado do sentido, a construção sutil e artificial das frases, tudo isto poderia consistir-se em outras tantas manifestações do espírito lúdico (Huizinga, 2001, p. 147).

A proximidade entre o jogo e a poesia configura um terreno fértil para a criação. Nos poemas de Saint-Denys Garneau podemos perceber como o jogo torna visível o invisível e transforma em móvel o que é fixo, constituindo-se em ferramenta de exploração do mundo e de experimentação poética. Ao encarar o jogo como recurso de criação poética, o poeta se vê livre das imposições de toda ordem preestabelecida. A partir dessa libertação, opera-se um jogo de variações, contrastes, ressonâncias, o qual permite um aprofundamento e um acúmulo de sentido em busca da verdade essencial das coisas.

Entre os vários elementos que compõem a poética de Saint-Denys Garneau, podemos destacar: o olhar como um lugar de encontro com o mundo, formando a base de uma poética do olhar; o mal-estar existencial do sujeito diante de um mundo que lhe é estranho e nocivo; o espírito da infância, presença marcante em vários poemas, cujas reverberações são um dos indícios da coerência da obra como um todo; a criação como recreação, ou seja, o fazer poético como jogo, onde estão implícitos o prazer da brincadeira, "Joie de jouer! paradis des libertés!", e também o rigor do jogo formal: "Ne me dérangez pas je suis profondément occupé"; bem como o movimento como fator de constituição da identidade do sujeito, através da noção de equilíbrio e oscilação no espaço.

No que diz respeito aos aspectos formais de sua poesia, apenas a título de introdução, o verso livre se faz presente de maneira majoritária (Garneau é considerado um dos precursores do verso livre no Québec), e não há regularidade das formas poéticas, já que os poemas não obedecem aos padrões clássicos estipulados pelo cânone literário; a presença de um ritmo característico da prosa também é notável, embora esse aspecto esteja sempre em função da geração do poético. Além disso, podemos identificar uma relativa ausência de pontuação, bem como o uso de uma sintaxe aparentemente truncada, mas totalmente a serviço do projeto de escritura poética de Saint-Denys Garneau.

\footnotetext{
${ }^{7}$ Versos do poema "Le jeu".
} 
Para melhor demonstrarmos os elementos acima referidos, tomaremos como objeto de leitura e análise o poema limiar de Regards et jeux dans l'espace, e também alguns trechos do poema $L e j e u$, que igualmente está presente no referido livro. Nosso intuito é o de problematizar algumas questões ligadas à poesia de Garneau para desvelar o funcionamento da geração oblíqua de sentido no referido poema.

A poesia de Saint-Denys Garneau está fortemente imbuída de uma recusa da estaticidade. Desde o título de seu primeiro e único livro de poemas, Regards et jeux dans l'espace, estão lançadas as bases de sua poética, profundamente relacionada ao olhar como instrumento de apreensão do mundo, ao movimento como meio de construção da identidade, e ao espaço como suporte de seus jogos poéticos.

Trata-se de uma poesia que busca estabelecer uma relação entre o sujeito e o mundo através do olhar. Nela, o olhar compreende e dispõe todas as coisas, e se torna um lugar de encontro com o mundo. Lançando um olhar poético sobre as coisas, Garneau cria, como já referimos, uma poética do olhar. $\mathrm{O}$ espaço que se estende entre os olhos e a realidade a ser observada é o campo aberto onde o poeta vai realizar seu jeu d'enfant, seus jogos poéticos. Nesse sentido, é preciso seguir a viagem do olhar nos poemas de Saint-Denys Garneau.

A partir daí temos também a noção de jogo, que pode ser entendida como a brincadeira de criança, presente como atividade lúdica e descompromissada com o utilitarismo material, mas também como um jogo formal capaz de agir na verdade essencial das coisas através da criação poética:

\section{Il vous arrange les mots comme si c'étaient de simples chansons \\ Et dans ses yeux on peut lire son espiègle plaisir À voir que sous les mots il déplace toutes choses ${ }^{8}$}

A brincadeira de criança se torna séria e compenetrada se pensarmos no significado do verbo arranger, que traz em si não só a ideia do arranjo (combinação dos elementos que fazem parte da brincadeira), mas também a da organização das palavras (ofício do poeta). A interação entre a imagem do menino-poeta e as palavras por ele dispostas revela uma verdade essencial que é trazida à tona pelo próprio olhar: "Et dans ses yeux on peut lire son espiègle plaisir / À voir que sous les mots il déplace toutes

\footnotetext{
${ }^{8}$ Trecho do poema "Le jeu".
} 
choses. " ${ }^{9}$ Esse prazer brincalhão está intimamente ligado à possibilidade que o menino tem de mover todas as coisas através das palavras. A partir desse ponto a brincadeira assume um papel central, pois é por meio dela que o poeta cria seu universo particular. Além disso, o último verso do excerto acima traz uma ideia caríssima à poesia de SaintDenys Garneau, através da qual o poeta engendra seus jogos poéticos: trata-se da ideia de movimento.

As noções de olhar e jogo são atravessadas pela noção de movimento, sendo que todas elas contribuem para uma problematização da identidade do sujeito da enunciação poética. Quem é esse poeta-menino, que faz da brincadeira o seu modo peculiar de fazer poesia?

Geneviève Boudreau aponta em Garneau uma busca de identidade que se dá através do que a autora chama de "poética do movimento." Em linhas gerais, o movimento é constitutivo da identidade do sujeito pois permite, através da oscilação entre um elemento identitário e outro, reunir os fragmentos do ser e através desse processo chegar a um estado de equilíbrio. A noção de movimento, portanto, faria parte de um jogo poético que permitiria ao sujeito, por meio da oscilação e do equilíbrio, construir sua própria identidade (Boudreau, 2009). O referido trabalho é sem dúvida uma importante contribuição para melhor compreender a obra poética de Saint-Denys Garneau. Sem dúvida, tanto o movimento quanto a busca pela identidade estão intimamente ligados na poesia de Garneau.

Para ilustrar as observações acima referidas, é de fundamental importância a leitura do poema limiar que abre o conjunto de poemas de Regards et jeux dans l'espace, o qual funciona como uma espécie de prefácio da obra. Lancemos um olhar sobre o referido poema:

\footnotetext{
Je ne suis pas bien du tout assis sur cette chaise

Et mon pire malaise est un fauteuil où l'on reste

Immanquablement je m'endors et j'y meurs.

Mais laissez-moi traverser le torrent sur les roches

Par bonds quitter cette chose pour celle-là

Je trouve l'équilibre impondérable entre les deux

C'est là sans appui que je me repose.
}

O sujeito enunciativo instaura um estado subjetivo no qual o desconforto e o

\footnotetext{
${ }^{9}$ Ibidem.
} 
mal-estar se fazem presentes: "Je ne suis pas bien du tout assis sur cette chaise / Et mon pire malaise est un fauteuil où l'on reste". A regularidade das formas e o caráter estático dos objetos chaise e fauteuil provocam no je uma inquietude que é fundamental em todo o conjunto da obra. Signo das imposições formais e até mesmo estéticas, tais objetos representam também o que a poesia de Saint-Denys Garneau vai negar através do jeu d'enfant, ou seja, todo o universo da ordem pré-estabelecida. Por isso esse desconforto, onde malaise, que aparece logo no segundo verso do poema, sugere a imagem poética de um menino que se agita na cadeira, inquieto, buscando uma maneira de fugir dessa situação de imobilidade.

A imobilidade em Garneau é tratada como algo a ser combatido, tornando-se, para o poeta, o berço da letargia e da morte: immanquablement je m'endors et j'y meurs. Por isso a inquietude, e o reforço da negação expressa no primeiro verso do poema limiar, onde o sujeito diz não estar nada bem: je ne suis pas bien du tout. Já não é mais possível apenas fugir dessa prisão em forma de poltrona, é preciso colocar-se em movimento para fazer o contraponto necessário a essa imobilidade.

Saint-Denys Garneau opera o movimento com maestria, instaurando imagens poéticas contrárias e oscilando entre elas. Esse processo se repete sistematicamente ao longo do conjunto de poemas de Regards et jeux dans l'espace, e fica mais do que evidente na segunda estrofe do poema-prefácio, em oposição à imobilidade da primeira estrofe. Através de uma simples conjunção, mais, que pode ter um valor adversativo mas também enfático, para reforçar o sentido de uma exclamação, o sujeito da enunciação no poema expressa o seu apreço pelo movimento, saltando de uma imagem poética a outra, como uma criança que atravessa brincando um riacho, sobre as pedras: "Mais laissez-moi traverser le torrent sur les roches / Par bonds quitter cette chose pour celle-là’.

Se o termo fauteuil representa a imobilidade, que podemos dizer do termo torrent, o qual se refere a um curso d'água íngreme, de fluxo rápido e irregular? Temos aí a força do movimento sob os pés do menino-poeta. Talvez essa brincadeira não seja tão comum no quotidiano das grandes cidades, mas em meio à natureza, repleta de riachos e torrentes, atravessá-los aos saltos, sobre as pedras, é um jogo pueril de valor inestimável para o poeta. O sujeito da enunciação está sempre em movimento, e esse movimento representa o impulso da vida. A partir dessa observação podemos opor as duas estrofes e dizer que ambas expressam morte e vida, respectivamente. E o que há entre uma estrofe e outra? O espaço em branco. Seria um tanto óbvio afirmar que o 
espaço é significativo, mas é justamente aí que reside a genialidade do poeta: ele está jogando com o espaço, buscando o "equilíbrio imponderável" entre as coisas. Por essa razão podemos afirmar que a simplicidade dos poemas de Regards et jeux dans l'espace é apenas aparente.

A mudança de posição no espaço encontra na poesia de Saint-Denys Garneau um lugar privilegiado, pois é constitutiva da própria identidade do sujeito: "Je trouve l'équilibre impondérable entre les deux". O poeta, transitando entre "cette chose" e "celle-là", encontra seu lugar numa posição intermediária entre as coisas, porém não determinada, pois faz parte de um “equilíbrio imponderável”. Não se trata de escolher uma ou outra, mas de buscar, no espaço entre as duas, seu lugar por excelência: " $C$ 'est là sans appui que je me repose”. Essa imagem poética, de extrema densidade, sugere a dança que o menino-poeta realiza ao atravessar a torrente sobre as rochas, pairando no ar entre um salto e outro.

Tais observações nos levam a formular uma simples questão: como o movimento pode revelar a composição da identidade do sujeito em Garneau? Do que vimos até este ponto, podemos dizer que o jogo e sua prática transgressiva, bem como as complexas relações estabelecidas pelo olhar, estão no coração do problema.

\section{Traduzindo os jogos no espaço de Saint-Denys Garneau}

Nesta seção trataremos de analisar o poema "C'est-là sans appui", trazendo à luz aspectos mais relevantes, discutindo as relações internas entre os elementos que o compõem, bem como as questões de forma que se apresentam. Uma vez realizada a discussão sobre o poema em si, partiremos para a tradução comentada do mesmo, expondo alguns critérios que nortearam as escolhas tradutórias, sempre a serviço da recriação, na língua de chegada, dos elementos mais expressivos presentes na língua de partida.

\section{Aí sem apoio: analisando o equilíbrio imponderável}

Consideremos o poema que abre a coletânea de Regards et jeux dans l'espace, o qual, como vimos anteriormente ao ilustramos a poética de Saint-Denys Garneau, funciona como uma espécie de prefácio, uma introdução ao seu universo poético. Apesar de se tratar de um poema sem título, as edições posteriores à de 1937 trazem um trecho retirado do mesmo que serve como tal. O poeta foi muito criticado pelo prosaismo e também pela presença de uma sintaxe aparentemente truncada, mas basta 
lançar um olhar mais cuidadoso a este poema e podemos perceber como cada elemento está operando perfeitamente em função do poético. Nele encontramos não só recursos recorrentes da poética de Garneau, mas também a afirmação do lugar do poeta no mundo, o que faz do poema uma peça fundamental no conjunto da obra.

\author{
C'est là sans appui \\ Je ne suis pas bien du tout assis sur cette chaise \\ Et mon pire malaise est un fauteuil où l'on reste \\ Immanquablement je m'endors et j'y meurs. \\ Mais laissez-moi traverser le torrent sur les roches \\ Par bonds quitter cette chose pour celle-là \\ Je trouve l'équilibre impondérable entre les deux \\ C'est là sans appui que je me repose.
}

Os primeiros versos apontam para um mal-estar existencial diante da estaticidade e da regularidade formal que impedem o sujeito de se ajustar à ordem imposta. Esse mal-estar é traduzido pela imobilidade do "fauteil où l'on reste." O je anuncia, logo no início, o perigo do estatismo: a imobilidade representa um fator negativo e indesejável, contra a qual será travada uma luta em forma de jogo. Permanecer imóvel sobre o fauteuil pode ser um risco mortal: "Immanquablement je m'endors et j'y meurs." Daí a necessidade, a partir dos versos da segunda estrofe, do movimento do ser. Veremos como, por meio do jogo, o sujeito da enunciação poética se contrapõe à estaticidade para enaltecer o dinamismo do movimento.

Retomando o primeiro verso, temos um sujeito (je) cuja existência está comprometida diante de um mal-estar no mundo material: "Je ne suis pas bien du tout assis sur cette chaise." A princípio, a expressão que indica o desconforto é um tanto quanto genérica, embora enfática, e não permite maiores elucubrações. É importante ressaltar que na poética de Saint-Denys Garneau ocorre um acúmulo de sentido que se estabelece pelas relações internas do poema. Ainda não podemos delinear os contornos desse incômodo presente em “Je ne suis pas bien du tout...", porém a intensidade trazida pelo segundo verso em "mon pire malaise" permite que vislumbremos a amplitude que esse desconforto adquire. Em ambos os versos, o mal-estar está relacionado aos objetos que servem de assento ao sujeito, o que necessariamente nos leva a investigar tais elementos a fim de melhor compreender essa angústia existencial anunciada. 
Se a poesia é a arte da linguagem que opera metaforicamente, e se a metáfora é, em linhas gerais, a comparação entre dois elementos distintos pelo que há de semelhante entre eles, podemos fazer a leitura de chaise e fauteuil como sendo os objetos que representam a imposição de uma ordem pré-estabelecida, cujas formas infligem ao sujeito um modo de estar no mundo alheio a seus anseios mais íntimos. O sofrimento infligido pela poltrona fica mais patente diante do dêitico "où l'on reste" (onde se fica), e aqui se explicita a aversão do sujeito a tudo que é imóvel, parado, sem vida. O terceiro verso nos dá prova de que essa chave de leitura é possível, já que a imobilidade da poltrona é considerada mortal pelo je. Agora temos uma definição mais palpável do mal-estar que o sujeito experimenta no poema, corroborada pelo advérbio que coroa seu sofrimento: immanquablement.

Uma vez anunciado o mal-estar, fonte de angústia e inquietação, tem início um jogo de contrastes ao qual nos atentaremos. O momento de transição da primeira para a segunda estrofe é mediado pelo uso de uma conjunção que introduz uma ideia contrária àquela expressa na primeira estrofe (imobilidade da poltrona, mal-estar do sujeito). A ocorrência do mais não se restringe apenas a uma conjunção adversativa, mas a um modus operandi embasado no movimento, na oscilação entre os contrários. O mais, no poema, corresponde ao que poderíamos chamar aqui de ponto de equilíbrio, pois não só marca a oposição entre uma estrofe e outra mas também entre uma metáfora e outra, entre a imobilidade da mobília e o movimento da torrente e do salto.

O poeta faz uso da imagem de um movimento brusco, o salto, para atingir um estado de repouso. Seria um paradoxo se pensássemos essas imagens contrárias sem levar em conta que é o movimento entre uma e outra que marca a geração do poético em Saint-Denys Garneau. O poema coloca a questão do movimento, da passagem entre uma coisa e outra, como sendo elemento constitutivo da identidade do sujeito: " $C$ 'est là sans appui que je me repose." Essa passagem é possível graças a uma brincadeira de criança, a de saltar de uma pedra a outra da torrente, atravessando a mesma. A alegria dessa brincadeira, bem típica das regiões onde correm as águas de degelo que descem das montanhas (Saint-Denys Garneau passou sua infância e o final de sua vida no solar da família, no vale do rio Jacques-Cartier, em Sainte-Catherine de Fossambault), é uma alegria que constitui um ponto fundamental na poética de Garneau, pois ela não está nem numa margem, nem na outra, mas na travessia, no momento do salto entre as pedras da torrente, "sans appui". A brincadeira de criança se converte em jogo formal, através do qual o poeta lança as bases de seu fazer poético. Nesse jogo, ele contrapõe 
par bonds, na segunda estrofe, a assis, na primeira; torrent, por sua vez, opõe-se a chaise e fauteuil.

Esses jogos no espaço são a afirmação de uma estética que tem como base o complexo movimento de ida e vinda entre as imagens poéticas, numa pendularidade investigativa. A própria forma do poema pode ser entendida como uma síntese dessa pendularidade, se levarmos em conta que as duas estrofes opõem estaticidade e movimento. Na primeira estrofe temos o mal-estar causado pela imobilidade da cadeira, da poltrona, onde infalivelmente o sujeito da enunciação adormece e morre, ao passo que, na segunda estrofe, o mesmo ganha vida durante a travessia da torrente.

Para entendermos melhor esse movimento, seria importante refletirmos acerca da noção de equilíbrio. O que é o equilíbrio? Qual é a sua natureza no universo poético de Saint-Denys Garneau? Onde ele se situa? O equilíbrio está nas idas e vindas entre uma coisa e outra, no espaço entre as imagens poéticas. Trata-se de uma ideia fundamental do universo poético de Saint-Denys Garneau. Através do equilíbrio operase um jogo de contrastes e variações sem que seja dada ênfase a um elemento ou outro, pois é na própria oscilação que o poeta vai buscar a reconciliação dos contrários pelo movimento: “Je trouve l'équilibre impondérable entre les deux / C'est là sans appui que je me repose." É importante refletir também sobre o adjetivo que qualifica esse equilíbrio. Não se trata de um equilíbrio estático, onde a resultante das forças que compõem o movimento é igual a zero. Em Garneau o equilíbrio organiza os elementos que o compõem de tal forma que nada é enfatizado. Estamos diante do equilíbrio imponderável, adjetivo esse que marca a relevância do fator acaso, presente tanto no jogo quanto na brincadeira.

A oscilação se expressa entre os pares de oposição, como morte / vida, ficção / real, estaticidade / movimento, porém trata-se de um tipo especial de movimento, pendular, como já o dissemos, no qual o poeta, sempre entre "cette chose" e "celle-là", faz da própria oscilação o seu lugar no espaço. Um outro ponto importante do poema é o uso do verbo quitter. Com esse verbo o poeta demonstra o seu desapego às coisas e às ideias, a exemplo do menino que deixa um brinquedo por outro. A poesia, em Garneau, está longe de ser a possessão do mundo através das palavras, pelo contrário: ela é a possibilidade do desprendimento que permite a travessia, levando o poeta a um lugar que é o não-lugar, o espaço do entre dois.

Essa oposição entre vida e morte se opera através de um jogo duplo: primeiro, o do menino que não consegue ficar parado por muito tempo na cadeira, e que, logo em 
seguida, faz da travessia da torrente, aos saltos, uma brincadeira que não tem outra função senão a de gerar prazer nela mesma; segundo, o jogo do poeta, que faz da experiência poética um meio de exteriorizar o conflito presente entre a vida e a morte, entre o mal-estar existencial e a alegria de viver. $\mathrm{O}$ sujeito se define então através da brincadeira e do jogo poético, caracterizando uma busca da identidade. A partir dessas considerações podemos pensar a respeito do je que aparece no poema como sendo tanto menino quanto poeta, e logo percebemos que há também uma oscilação entre essas duas esferas. O equilíbrio imponderável se situaria entre o registro do particular e do geral.

Como já dissemos, a oposição entre morte e vida, ou estaticidade e movimento, está expressa na forma do poema: duas estrofes que se contrapõem mas que não se anulam entre si, e que encontram no espaço em branco um ponto de equilíbrio que é também lugar de passagem entre uma metáfora e outra. Interessante notar que é exatamente no espaço entre dois ("cette chose et celle-là") que o poeta encontra seu repouso, profundamente ligado ao movimento do ser.

Trata-se de uma proposta bastante ousada para os padrões estéticos e literários de uma época onde imperavam as formas clássicas e o verso alexandrino. Os versos do poema que abre a coletânea Regards et jeux dans l'espace orbitam na atmosfera do alexandrino, como bem aponta Michel Lemaire, oscilando entre 11 e 14 sílabas poéticas. Segundo o autor, essa seria uma forma de escamotear o verso clássico de maneira consciente e coerente com sua verdade interior (Lemaire, 1994, p. 80). Daí o poeta ter antecipado, já no poema prefácio, o seu mal-estar diante das imposições. A escolha pelo jogo ou brincadeira como forma poética de investigação do mundo e da linguagem é evidente neste poema limiar, e isso faz dele um dos mais representativos da poética de Saint-Denys Garneau.

Diante dessas considerações acerca do poema, apresentamos abaixo uma possível tradução, e a seguir passaremos a comentar as escolhas tradutórias e suas justificativas.

\section{Tradução comentada do poema limiar}

C'est là sans appui

Je ne suis pas bien du tout assis sur cette chaise Et mon pire malaise est un fauteuil où l'on reste Immanquablement je m'endors et j'y meurs.
Aí sem apoio

Eu não estou nada bem aqui nesta cadeira E meu pior mal-estar é uma poltrona onde ficar Infalivelmente adormeço ali morro 
Mais laissez-moi traverser le torrent sur les roches

Par bonds quitter cette chose pour celle-là Je trouve l'équilibre impondérable entre les deux $C$ 'est là sans appui que je me repose.
Mas me deixe atravessar a torrente sobre as rochas Em saltos deixar esta coisa por aquela Encontro o equilíbrio imponderável entre as duas Aí sem apoio é que eu repouso.

Comentaremos, a seguir, as questões de maior relevância que foram surgindo durante o processo de tradução, entre elas a permanência de um tom coloquial (prosaísmo), o ritmo característico do poema, a supressão dos pronomes pessoais, os mecanismos de compensação de algumas imagens poéticas, bem como a escolha de determinados vocábulos.

Existe um ritmo no poema, evidentemente ligado à prosa, a uma maneira menos empolada de falar, enfim, a um tom mais coloquial, que é preciso levar em conta na tradução. Mesmo em se tratando de um prosaísmo historicamente marcado (lembremos a estranheza que a poesia de Garneau causou na crítica mais descuidada), é possível identificar os elementos mais universais que compõem esse prosaísmo: a presença de uma linguagem informal, baseada na familiaridade com os objetos do cotidiano (chaise, fauteuil), além da simplicidade de certos vocábulos. Até a palavra mais carregada de formalidade, immanquablement, está a serviço da construção de um acúmulo de sentido que culmina na morte do sujeito diante da estaticidade. Em vista disso, um ponto importante da tradução é o de recriar esse ritmo prosaico e essa linguagem informal em função da própria poética de Saint-Denys Garneau.

Como as edições de Regards et jeux dans l'espace posteriores à de 1949 trazem um título extraído dos versos do poema (título esse que não existia na primeira edição, de 1937), o problema de sua tradução já nos leva a uma reflexão em torno das possíveis escolhas. Para traduzir a expressão c'est là de maneira satisfatória, foi preciso pensar a respeito da natureza desse lugar, já que a expressão marca um dêitico que tanto pode se referir a um lugar diferente daquele em que se está, como ao próprio lugar em que se encontra o enunciador. A análise anterior do poema nos ajudou a resolver a questão, pois sabemos que esse lugar é o não-lugar, situado no entre dois, entre uma coisa e outra. Não pode coincidir, portanto, com o lugar do enunciador. Assim, para manter o ritmo prosaico e truncado do poema original, optou-se pelo dêitico aí, pois além de marcar o lugar funciona em consonância com o présentatif (muito recorrente nos poemas de Garneau), que inicia o último verso. Assim, o c'est là transformou-se no hiato aí, e com isso criou-se um efeito lacunar, como se algo estivesse fora do lugar. $\mathrm{O}$ resultado se mostrou adequado ao ritmo do poema. 
Pareceu-nos fundamental manter o je do primeiro verso, optando por uma tradução expressa do pronome em vez de suprimir um $E u$ possível. Sabemos que o francês é uma língua que exige as marcas enunciativas do sujeito, ou seja, os pronomes que indicam as pessoas do discurso:

[...] os pronomes que precedem os verbos conjugados são, em francês, chamados de pronoms de conjugaison, pois, foneticamente, as pessoas verbais não são marcadas, logo, o pronome é a marca de pessoa e, por isso, indispensável; já em português, o uso do pronome sujeito é, em geral, falha de estilo, uma vez que a terminação verbal marca a pessoa (Faleiros, 2012, p. 101).

O português, como vimos acima, permite certa economia e adequação de estilo. Apesar disso, a primeira estrofe do poema requer uma marca de sujeito, pois ela toda expressa uma singularidade do mesmo, daí a importância de enfatizar o $e u$ através de sua própria presença encarnada no pronome. Com isso a tradução abre caminho para o acúmulo de sentido que vai desembocar no mal-estar.

Ainda no primeiro verso, a escolha do termo "aqui" — no lugar de assis demonstra um mecanismo de compensação interessante. Já que os elementos chaise e fauteuil pressupõem que o sujeito da enunciação esteja sentado, buscou-se uma homofonia vocálica entre as palavras assis e aqui com o intuito não só de recriar a sonoridade do verso mas também de compensar a perda de sentido do particípio verbal assis, uma vez que o dêitico aqui reforça a situação do sujeito, preso ao espaço da cadeira e da poltrona. Tentou-se, com isso, amenizar a perda da imagem poética presente em assis, que se contrapõe, como vimos na análise, aos saltos sobre a torrente. Ocorreu um processo similar no uso do "ali" em lugar do pronome $y$, e assim obtivemos "ali morro".

Outra compensação ocorreu no segundo verso, pois a difícil tradução do pronome on, índice de indeterminação do sujeito, levou-nos ao uso do infinitivo "ficar". As reverberações de malaise em où l'on reste não são gratuitas no poema original, e precisavam aparecer, de alguma forma, em nossa tradução. Por essa razão optou-se pelo uso do verbo "ficar", uma vez que estabelece uma rima interna com o termo "malestar". Não se trata apenas de uma compensação sonora, mas também de sentido. Buscou-se, com esse expediente, recriar o acúmulo de sentido mencionado anteriormente.

A segunda estrofe do poema, curiosamente, foi a parte mais lúdica, digamos, do 
ato tradutório. A presença de algumas aliterações desvelaram um jogo mimético do barulho das águas da torrente, do ruído dos saltos do menino-poeta. Tentamos, na medida do possível, reproduzir esse efeito, mantendo a cognata "torrente", já que se trata efetivamente de um curso de água bastante peculiar. Além disso, a palavra “torrente" faz um eco consonantal em "atravessar", reproduzindo em parte as aliterações do poema original.

O verso que abre a segunda estância do poema apresenta, predominantemente, a repetição da consoante $r$, mas também aparece a aliteração do $t$ entre as palavras traverser e torrent. Fica clara a existência de um jogo poético que relaciona a travessia à torrente em termos fonéticos, talvez com o objetivo de sugerir a mímese dos sons característicos da torrente. Nossa tradução, levando em consideração as observações acima, parte do pressuposto de que tal jogo constitui essência sonora extremamente significativa, a qual deve ser recriada na língua de chegada. Assim, "atravessar" e "torrente", ao lado de "sobre" e "rochas", servem a esse propósito, uma vez que aí temos a repetição tanto do $r$ quanto do $t$ : "Mas me deixe atravessar a torrente sobre as rochas."

Percebemos que o sujeito da enunciação está sempre em movimento, principalmente a partir da segunda estrofe. Tentamos, na tradução, recriar o dinamismo do ser a fim de nos mantermos fiéis a este elemento de fundamental importância na poética de Saint-Denys Garneau. No entanto, a tarefa mais difícil na tradução deste poema foi a de encontrar o equilíbrio imponderável entre uma estrofe e outra, mantendo a visilegibilidade, nos termos em que a define Laranjeira:

Existe [...] uma pré-leitura visual, baseada na distribuição espacial da massa textual, gráfica, do poema, e esta não é propriamente nem linear, nem retroativa. Ela não participa da discursividade linguística, sendo antes uma percepção global e acrônica, não sequencial, à maneira da que se dá em relação às artes plásticas (Laranjeira, 2003, p. 101).

Essa pré-leitura visual do poema pode indicar uma primeira estrofe mais regular, com versos aproximadamente da mesma medida no que diz respeito à sua disposição gráfica, ao passo que a segunda estrofe, que versa sobre o movimento constitutivo da identidade do sujeito, apresenta uma estruturação mais irregular, sugerindo, talvez, o próprio movimento através desse arranjo. Ainda de acordo com Mário Laranjeira: "Para o tradutor de poemas, a tradução começa pela transposição da visilegibilidade." (Laranjeira, 2003, p. 103). A configuração espacial do poema em Garneau é sem dúvida 
um elemento que contribui para gerar a significância do poema, e deve ser observada. Sensível a esse detalhe, nossa tradução procurou manter uma disposição gráfica similar à do poema original.

$\mathrm{O}$ ato tradutório em poesia deve superar a simples transposição de vocábulos de uma língua para outra. "O tradutor tem de ter em conta a questão da interpretação para além do problema de selecionar, na língua de chegada, uma frase de sentido minimamente parecido" (Bassnet, 2003, p. 48). Nesse sentido, tratamos de considerar o poema com um todo organizado em torno de suas relações internas. "Ora, se é o poema todo que constitui a unidade de significância, também será o poema toda a unidade de tradução poética.]" (Laranjeira, 2003, p. 84).

\section{Conclusão}

O presente artigo buscou introduzir o leitor no universo poético de Saint-Denys Garneau, trazendo à tona dados de sua biografia bem como algumas das características mais importantes de seu fazer poético. Além disso, ilustramos a poética do autor com base na leitura e análise do poema C'est là sans appui, que abre a coletânea Regards et jeux dans l'espace, e apresentamos uma tradução comentada do mesmo, com o objetivo de permitir aos leitores de poesia em língua portuguesa o acesso a uma pequena parte da obra de Garneau.

Vimos que sua poesia configura-se como uma possibilidade de expressão dos conflitos metafísicos, onde o sujeito experimenta um mal-estar existencial diante de um mundo que lhe é estranho e nocivo. Examinamos que se trata de uma poesia que busca estabelecer uma relação entre o sujeito e o mundo através do olhar, e pudemos observar que a recusa da estaticidade em Garneau gera o movimento como fator de constituição da identidade do sujeito, um ponto central em sua poética. Verificamos, também, como a proximidade entre o jogo e a poesia configura um terreno fértil para a criação poética de Saint-Denys Garneau.

Tratamos de recriar, na língua de chegada, os jogos poéticos de Saint-Denys Garneau, levando em consideração o tom coloquial do poema, suas relações internas, seus acúmulos de sentido e sua visilegibilidade, e com isso ofertamos aos leitores de poesia em língua portuguesa a primeira tradução do poema $C^{\prime}$ est là sans appui. 


\section{Referências bibliográficas:}

BASSNETT, Susan. Estudos de tradução: fundamentos de uma disciplina. Trad. de Vivina de Campos Figueiredo. Lisboa: Fundação Calouste Gulbenkian, 2003.

BOUDREAU, Geneviève. L'équilibre impondérable. Identité et mouvement dans Regards et jeux dans l'espace d'Hector de Saint-Denys Garneau. 2009, 97 p. Dissertação, Faculté des Lettres — Université Laval, Québec - 2009.

EVEN-ZOHAR, Itamar. The position of translated literature within the literary polysistem. In: VENUTI, Lawrence (org.). The translation studies reader. Nova York \& Londres: Routledge, 2000, p. 199-204.

FALEIROS, Álvaro. Traduzir o poema. São Paulo: Ateliê Editorial, 2012.

GARNEAU, Hector de Saint-Denys. Regards et jeux dans l'espace / Les solitudes. Montreal: Bibliothèque Québecoise, 1993. Regards et Jeux dans l'Espace / Les Solitudes. Montréal: Fides, 1972.

GASQUY-RESCH, Yannick et al. Littérature du Québec. Paris: Édicef/Aupelf, 1994.

HUIZINGA, Johan. Homo ludens. 5ª ed. São Paulo: Perspectiva, 2000.

LAFETÁ, João Luiz. 1930: A crítica e o modernismo. São Paulo: Duas Cidades/Editora $34,2000$.

LARANJEIRA, Mário. Poética da tradução: do sentido à significância. São Paulo: Edusp, 2003.

LEMAIRE, Michel. "Métrique et prosaïsme dans la poésie de Saint-Denys Garneau". Voix et Images, vol. 20, n 1, (58) 1994, p. 73-84.

ROY, Mgr. Camille. Manuel d'histoire de la littérature canadienne de langue française.21 ème edition, revue et corrigée par l'auteur, Montréal, Beauchemin, 1962 [1939], 201p., p. 102-125. Disponível em:

http://faculty.marianopolis.edu/c.belanger/quebechistory/encyclopedia/roylitchap10.htm (último acesso em 02/11/2013)

\section{Sites consultados:}

Hector de Saint-Denys Garneau - Site oficial sobre o poeta http://www.saintdenysgarneau.com (último acesso em 28/10/2013)

L'Encyclopédie de l'histoire du Québec http://faculty.marianopolis.edu/c.belanger/quebechistory/encyclopedia/roylitchap10.htm (último acesso em 28/10/2013) 